\title{
Cannabinoid Modulation of Food-Cocaine Choice in Male Rhesus Monkeys
}

\author{
William S. John, ${ }^{1}$ Thomas J. Martin, and Michael A. Nader \\ Departments of Physiology and Pharmacology (W.S.J., M.A.N.) and Anesthesiology (T.J.M.), Wake Forest School of Medicine, \\ Winston-Salem, North Carolina
}

Received November 5, 2019; accepted January 8, 2020

\begin{abstract}
Marijuana and other cannabinoid compounds are widely used by cocaine users. Preclinical animal studies suggest that these compounds can increase the reinforcing effects of cocaine under some schedules of cocaine self-administration and reinstatement, but not in all cases. To date, no studies have used a food-cocaine concurrent choice procedure, which allows for assessment of drug effects on response allocation, not just changes in cocaine self-administration. The goal of the present study was to examine the effects of compounds differing in their efficacy at the cannabinoid receptor (CBR) on cocaine selfadministration using a food-drug choice procedure in monkeys. Four adult male rhesus monkeys were trained to self-administer cocaine in the context of an alternative food (1.0-g bananaflavored pellets) reinforcer, such that complete cocaine doseresponse curves $(0,0.003-0.1 \mathrm{mg} / \mathrm{kg}$ per injection) were determined each session. Monkeys were tested acutely with the CBR full agonist CP 55,940 (0.001-0.01 mg/kg); the CBR
\end{abstract}

partial agonist $\Delta^{9}$-tetrahydrocannabinol (THC; $0.03-0.3 \mathrm{mg} / \mathrm{kg}$ ), which is also the primary active ingredient in marijuana and the CBR antagonist rimonabant $(0.3-3.0 \mathrm{mg} / \mathrm{kg})$. Cocaine choice increased in a dose-dependent manner. Acute treatment with CP 55,940 decreased cocaine choice, whereas THC and rimonabant enhanced the reinforcing effects of cocaine. Chronic (7-day) treatment with CP 55,940 resulted in tolerance to the decreases in cocaine choice. These findings with $\Delta^{9}-\mathrm{THC}$ provide support for a potential mechanism for co-abuse of marijuana and cocaine. Additional research with chronic treatment with full CBR agonists on attenuating the reinforcing strength of cocaine is warranted.

\section{SIGNIFICANCE STATEMENT}

Co-abuse of tetrahydrocannabinol and cocaine is a significant public health problem. The use of animal models allows for the determination of how cannabinoid receptor stimulation or blockade influences the reinforcing strength of cocaine.

\section{Introduction}

Emerging evidence has implicated the endocannabinoid system in modulating the abuse-related effects of cocaine. The endocannabinoid system is composed of two major types of cannabinoid receptors (CBRs), the cannabinoid type 1 (CB1) and type 2 receptor, which are both inhibitory G-protein coupled receptors (Vlachou and Panagis, 2014). Pharmacological studies involving CBR ligands show that they interact with cocaine under a broad range of behavioral measures (Wiskerke et al., 2008; Olière et al., 2013). Further investigation of these interactions has implications for understanding aspects of polydrug use involving cocaine and cannabinoids as well as developing novel medications for cocaine use disorder.

In general, preclinical studies suggest that pharmacological antagonism of CBR inhibit (e.g., Gobira et al., 2019) or have no effect, whereas CBR agonists facilitate the behavioral effects

This work was supported by the National Institutes of Health National Institute on Drug Abuse [Grant P50 DA06634 (M.A.N., T.J.M.) and Grant F31 DA041825 (W.S.J.)]

${ }^{1}$ Current affiliation: Department of Psychiatry and Behavioral Sciences, Duke University Medical Center, Division of Social \& Community Psychiatry, Durham, North Carolina.

https://doi.org/10.1124/jpet.119.263707. of cocaine (Parsons and Hurd, 2015). Nonetheless, varying results have been found depending on the conditions under which the drugs are studied. For example, studies in rodents show that acquisition of cocaine self-administration was unaffected by treatment with the nonselective CBR antagonist SR141716A (Lesscher et al., 2005) or CBR partial agonist $\Delta^{9}$ tetrahydrocannabinol (THC) (Panlilio et al., 2007) but was increased by treatment with the agonist CP 55,940 (HigueraMatas et al., 2008). Consistent with this finding, adolescent $\Delta^{9}$-THC exposure resulted in increased acquisition of cocaine self-administration and increases in the reinforcing strength of low doses of cocaine in adults (Friedman et al., 2019). On the other hand, cocaine- and cue-induced reinstatement of extinguished cocaine self-administration has been found to be attenuated by CBR antagonists (De Vries et al., 2001; Filip et al., 2006; Xi et al., 2006; Ward et al., 2009; Adamczyk et al., 2012) but enhanced by pretreatment with $\Delta^{9}$-THC (Justinova et al., 2008) or the nonselective CBR agonist HU210 (De Vries et al., 2001). With regard to maintenance of cocaine selfadministration, the effects of CBR antagonists appear to be reinforcement-schedule dependent. That is, several reports show that pretreatment with SR141716A had no effect on cocaine self-administration under a fixed-ratio (FR) schedule of reinforcement in rodents (De Vries et al., 2001; Caillé and

ABBREVIATIONS: CB1, cannabinoid type 1; CBR, cannabinoid receptor; DA, dopamine; FR, fixed-ratio; PR, progressive-ratio; THC, tetrahydrocannabinol. 
Parsons, 2006; Filip et al., 2006) or nonhuman primates (Tanda et al., 2000) but decreased self-administration under a progressive-ratio (PR) schedule (Soria et al., 2005; Panlilio et al., 2007; Orio et al., 2009). Paradoxically, it has been found that pretreatment with $\Delta^{9}$-THC and the CBR agonist WIN 55,212 also decreased cocaine self-administration under PR (Panlilio et al., 2007) and FR1 (Fattore et al., 1999) schedules of reinforcement. However, it should be noted that the exact nature of the latter finding remains unclear as WIN 55,212 was not tested on the full cocaine self-administration doseresponse curve.

The goal of the present study was to further investigate the effects of CBR modulation on cocaine self-administration in the context of a food-drug choice procedure. It has been suggested that the use of a choice procedure is advantageous because it confers greater predictive validity of drug interactions than simple schedules of reinforcement (Banks and Negus, 2017). That is, substance use disorder has been conceptualized as a "disorder of choice" related to the disproportionate allocation of behavior toward substance procurement and use over nondrug reinforcers (Heyman, 2009; Banks and Negus, 2012). Consequently, a primary goal of treatment is to not only reduce substance use but to also reallocate behavior to more adaptive alternative reinforcers (Comer et al., 2008; Haney and Spealman, 2008; Banks and Negus, 2012). The majority of studies examining the interactions of CBR compounds on cocaine self-administration have been evaluated under FR schedules of reinforcement. Thus, the present study is a critical extension of earlier research.

Here, we examined the acute effects of three different CBR compounds on cocaine self-administration using a food-drug choice procedure. The compounds examined included the nonselective full CBR agonist CP 55,940, the nonselective CBR partial agonist $\Delta^{9}-\mathrm{THC}$, and the CBR inverse agonist/ antagonist rimonabant. We hypothesized that the effects of CBR compounds on food-cocaine choice would differ as a function of their efficacy at cannabinoid receptors. More specifically, because it has been shown that administration of CP 55,940 increases dopamine (DA) concentrations (Cheer et al., 2007; Wang et al., 2015), we hypothesized this compound would shift the cocaine dose-response curve to the right, whereas rimonabant, because CBR antagonists have been shown to decrease DA concentrations (Xi et al., 2008), would shift the cocaine dose-response curve to the left. It was not clear how $\Delta^{9}$-THC would affect cocaine choice. We also extended the effects of acute CP 55,940 to include 7-day treatment to examine whether tolerance developed to the effects on cocaine choice.

\section{Methods}

Subjects. Four adult male rhesus monkeys (Macaca mulatta), weighing $8.8-9.2 \mathrm{~kg}$ at the start of the study, and with a history of cocaine self-administration (John et al., 2015), served as subjects. Monkeys were fed enough food daily (LabDiet 5045; Purina, St. Louis, MO) to maintain healthy body weights ( 98\% free-feeding weights); water was available ad libitum in the home cage. Monkeys were individually housed in stainless steel cages, fitted with an aluminum collar, and trained to sit in a primate restraint chair (Primate Products, Redwood City, CA). Environmental enrichment was provided as outlined in the Animal Care and Use Committee of Wake Forest University Non-Human Primate Environment Enrichment Plan. Animal housing, handling, and experimental procedures met the
2011 National Research Council Guidelines for the Care and Use of Mammals in Neuroscience and Behavioral Research. The environmental enrichment plan was approved by the Wake Forest University Animal Care and Use Committee.

Surgery. Under ketamine (initial dose of $15 \mathrm{mg} / \mathrm{kg}$, i.m.) and isoflurane anesthesia, each monkey was implanted with a chronic indwelling intravenous catheter, surgically placed in a major vein (femoral or internal or external jugular), and subcutaneous vascular access port (Access Technologies, Skokie, IL) under aseptic conditions. One hour after surgery, animals were administered $30 \mathrm{mg} / \mathrm{kg}$ kefzol, i.m. (cefazolin sodium; Marsam Pharamaceuticals, Inc., Cherry Hill, NJ). Metacam (meloxicam; $0.1 \mathrm{mg} / \mathrm{kg}$, i.m.; Putney Inc., Portland, $\mathrm{ME}$ ), an analgesic, was administered once a day for 3 days.

Behavioral Procedure. Food-cocaine choice sessions were conducted daily in ventilated, sound-attenuating chambers $(1.5 \times 0.74 \times$ $0.76 \mathrm{~m}$; Med Associates, St. Albans, VT). Two photo-optic switches (Model 117-1007; Stewart Ergonomics, Inc., Furlong, PA), in which responses were recorded, were located on each side of an operant panel. Three stimulus lights, located in a horizontal row, were positioned $14 \mathrm{~cm}$ above each switch. Between each photo-optic switch was a food receptacle, which was connected to a pellet dispenser (Med Associates) with a Tygon tube. The pellet dispenser was located on the top of the chamber and delivered 1.0-g banana-flavored food pellets (Bio-Serv, Frenchtown, NJ). Also located on top of the chamber was a peristaltic infusion pump (Cole-Parmer Instrument Co., Niles, IL), which delivered drugs at a rate of approximately $1.5 \mathrm{ml}$ over 10 seconds.

Prior to the start of the experimental session, the area of the monkey's back near the vascular access port was cleaned with chlorhexidine and isopropyl alcohol swabs (Prevantics, Orangeburg, $\mathrm{NY}$ ). The venous catheter was connected to the infusion pump with the insertion of a 22-gauge Huber Point Needle (Access Technologies) into the port. The port was filled with the concentration of drug available that session by operating the pump for approximately 3 seconds. Pretreatment drug administration was given outside the chamber immediately before the session, and the monkey was placed into the operant chamber. To prevent clotting, catheters were flushed with $3 \mathrm{ml}$ of $100 \mathrm{U} / \mathrm{ml}$ heparinized saline at the end of the session.

The food-cocaine choice procedure was a multiple concurrent fixedratio schedule consisting of five 20 -minute components, which were separated from each other by a 5-minute timeout period. During each component, monkeys completed an FR requirement to receive food pellets and/or intravenous injections of cocaine. Food pellets were available in each component; the unit doses of cocaine available during each of the five successive components were $0,0.003,0.01,0.03$, and $0.1 \mathrm{mg} / \mathrm{kg}$ per injection, respectively. Different discriminative stimuli signaled the availability of each reinforcer such that illumination of a green light above one switch signaled food availability, whereas illumination of combinations of lights signaled different cocaine doses. The drug dose was varied by manipulating the pump duration and consequently the volume delivered. A total of 10 reinforcers were available in each component; components ended after 10 total reinforcers (food + cocaine injections) or 20 minutes had elapsed, whichever came first. In situations where 10 reinforcers were earned, the timeout component was added to the remainder of the component time to assure 2-hour sessions. In the event that a monkey emitted a response on the alternate switch before an FR was completed, the FR requirement on the first switch was reset. Illumination of the red light (conditioned stimulus; CS) in the center of the response panel, above the food receptacle, accompanied each cocaine injection. There was a 30-second timeout after each reinforcer (food or drug). Food and cocaine FR requirements were adjusted for each monkey to assure dose-dependent increases in cocaine choice (Table 1). Sessions were conducted typically 5-7 days per week.

Stable responding was defined as three consecutive sessions in which $\leq 20 \%$ of reinforcers earned on the cocaine switch when the alternative to food was no injection (component 1) or $0.003 \mathrm{mg} / \mathrm{kg}$ per injection cocaine (component 2 ) and $\geq 80 \%$ of reinforcers earned on the 
TABLE 1

Parameters for individual monkeys

\begin{tabular}{ccc}
\hline Subject & Food FR & Cocaine FR \\
\hline R-1661 & 50 & 10 \\
R-1688 & 50 & 60 \\
R-1689 & 10 & 100 \\
R-1692 & 50 & 120 \\
\hline
\end{tabular}

cocaine switch when the alternative to food was $0.1 \mathrm{mg} / \mathrm{kg}$ per injection cocaine (component 5). Once responding was stable, dose-response curves were conducted to determine the acute effects of $\Delta^{9}$-THC (0.03-0.3 mg/kg), CP 55,940 (0.001-0.01 mg/kg), and rimonabant (0.3-3.0 $\mathrm{mg} / \mathrm{kg}$ ), administered intravenously, immediately before the food-cocaine session. Doses were tested typically twice per week, with at least 2 days between test sessions. Pretreatment with the vehicle of each compound was tested each week as well. The effect of each acute dose was double or triple determined depending on variability between the first two tests.

Because the effects of acute CP 55,940 were positive (i.e., decreases in percent cocaine choice), the "best dose" of CP 55,940 was tested over seven consecutive sessions. "Best dose" was defined as the dose of CP 55,940 that either decreased cocaine choice or the highest dose that did not substantially disrupt responding, defined as a reduction in total trials by greater than $50 \%$. The "best dose" was $0.003 \mathrm{mg} / \mathrm{kg}$ for R-1661 and R-1688, $0.01 \mathrm{mg} / \mathrm{kg}$ for R-1692 and $0.017 \mathrm{mg} / \mathrm{kg}$ for R-1689.

Data Analysis. The primary dependent variable was percent cocaine choice defined as (number of cocaine injections $\div$ total number of reinforcers $) \times 100$. In addition, total reinforcers per session, total food reinforcers, and total cocaine injections are shown. Acute pretreatment dose-effect curves for CP 55,950, $\Delta^{9}$-THC, and rimonabant included the average of at least two determinations for each monkey. Data for the effects of chronic CP 55,940 treatment on cocaine choice were shown as a single determination on day 7 of treatment of each monkey. The group mean of these data were analyzed using repeatedmeasures two-way ANOVA, with cocaine dose and treatment as the main factors. The total cocaine intake per session was also determined and analyzed using repeated-measures one-way ANOVA across treatment drug conditions. A significant ANOVA was followed by multiple comparisons post hoc tests to compare test conditions with vehicle conditions. The criterion for significance was set a priori at the $95 \%$ level of confidence $(P<0.05)$ in all cases. All analyses were conducted with Prism 6 for Mac OS X software (GraphPad Software, Inc.).

Drugs. Cocaine, $\Delta^{9}$-THC, CP 55,940, and rimonabant were all obtained from the National Institute on Drug Abuse, Bethesda, MD. (-)-Cocaine $\mathrm{HCl}$ was dissolved in sterile $0.9 \%$ saline. $\Delta^{9}-\mathrm{THC}, \mathrm{CP}$ 55,940 , and rimonabant were dissolved in a vehicle containing one part Tween 80, one part ethanol, and 18 parts sterile water. Each compound was administered intravenously, through the vascular access port, followed by a 3-ml saline injection to ensure the entire dose was delivered.

\section{Results}

After vehicle pretreatment (closed circles, Fig. 1), monkeys primarily chose food when the alternative was either no injection of cocaine (component 1) or a low unit dose of cocaine $(0.003 \mathrm{mg} / \mathrm{kg})$. Behavior was almost exclusively reallocated to cocaine choice during the availability of larger unit cocaine doses $(0.01-0.1 \mathrm{mg} / \mathrm{kg})$. The maximum number of 10 reinforcers was typically earned in each component except the last two components when the two highest unit doses of cocaine $(0.03-0.1 \mathrm{mg} / \mathrm{kg}$ ) were available (closed circles, Fig. 2, A-C). During components 1 and 2, the majority of the reinforcers earned was food (closed circles, Fig. 2, D-F), with increases in the frequency of cocaine injections associated with higher cocaine doses (closed circles, Fig. 2, G-I).

Acute pretreatment with $\mathrm{CP} 55,940$ decreased cocaine choice compared with vehicle (Fig. 1A). There was a significant interaction between cocaine dose and CP 55,940 dose $\left(\mathrm{F}_{12,36}=\right.$ $2.80, P<0.01$ ), and post hoc analysis indicated a significant decrease in percent choice of $0.01 \mathrm{mg} / \mathrm{kg}$ cocaine after administration of $0.01 \mathrm{mg} / \mathrm{kg}$ CP 55,940 compared with vehicle pretreatment $(P<0.05)$. There was a significant interaction between cocaine dose and CP 55,940 dose for total reinforcers earned $\left(\mathrm{F}_{12,36}=2.18, P<0.05\right)$, with $\mathrm{CP} 55,940$ dosedependently increasing total reinforcers in components 4 and 5 (Fig. 2A). After CP 55,940, there were significant increases in food reinforcers earned $\left(\mathrm{F}_{12,36}=3.93, P<0.001\right.$; Fig. 2D). Higher doses of CP 55,950 decreased food pellets earned in the first two components and significantly increased food reinforcers in component 3 , consistent with the decrease in cocaine choice in this component. There was a main effect of $\mathrm{CP}$ 55,940 dose on cocaine injections $\left(\mathrm{F}_{9,27}=2.79, P<0.05\right)$, with decreases observed in component 2 (Fig. 2G).

In contrast to the effects with CP 55,940, pretreatment with $\Delta^{9}$-THC increased cocaine choice compared with vehicle pretreatment (Fig. 1B). There was a significant main effect for $\Delta^{9}$ THC dose on choice $\left(\mathrm{F}_{3,51}=3.62, P<0.05\right)$ and a significant interaction between cocaine dose and $\Delta^{9}$-THC dose $\left(\mathrm{F}_{12,51}=\right.$ $4.08, P<0.001)$. Post hoc analyses indicated that each dose of $\Delta^{9}$-THC $(0.03-0.3 \mathrm{mg} / \mathrm{kg})$ significantly increased choice for $0.003 \mathrm{mg} / \mathrm{kg}$ per injection cocaine compared with vehicle pretreatment $(P<0.0001) . \Delta^{9}$-THC administration decreased the total reinforcers earned per session $\left(\mathrm{F}_{3,9}=20.06, P<\right.$ 0.001 ), with significance noted after the highest $\Delta^{9}$-THC dose (Fig. 2B). There was a significant main effect $\left(\mathrm{F}_{3,9}=15.80, P<\right.$ $0.001)$ and a significant interaction $\left(\mathrm{F}_{12,36}=9.30, P<0.0001\right)$ of cocaine dose and $\Delta^{9}$-THC dose on food reinforcers (Fig. 2E). Consistent with the increase in cocaine choice, post hoc analyses showed a dose-dependent decrease in food pellets earned in the first two components. There was a significant main effect $\left(\mathrm{F}_{3,9}=6.26, P<0.05\right)$ and a significant interaction between cocaine dose and $\Delta^{9}$-THC dose for cocaine injections earned $\left(\mathrm{F}_{9,27}=3.68, P<0.01\right.$; Fig. $\left.2 \mathrm{H}\right)$. In addition to significant decreases in total reinforcers (Fig. 2B), the highest dose of $\Delta^{9}$-THC $(0.3 \mathrm{mg} / \mathrm{kg})$ produced significant decreases in injections of 0.01 and $0.03 \mathrm{mg} / \mathrm{kg}$ cocaine compared with vehicle pretreatment.

The results from rimonabant pretreatment were qualitatively similar to $\Delta^{9}$-THC pretreatment. That is, rimonabant produced an increase in choice of the low cocaine dose $(0.003 \mathrm{mg} / \mathrm{kg}$ per injection) in which there was a significant interaction for choice between cocaine and rimonabant dose $\left(\mathrm{F}_{12,57}=2.16, P<0.05\right.$; Fig. $\left.1 \mathrm{C}\right)$. There was also a main effect of rimonabant dose for total reinforcers earned $\left(\mathrm{F}_{3,9}=9.17\right.$, $P<0.01$; Fig. 2C) and a significant interaction between cocaine dose and rimonabant dose for total reinforcers $\left(\mathrm{F}_{12,36}\right.$ $=2.28, P<0.05$; Fig. $2 \mathrm{C})$, food reinforcers $\left(\mathrm{F}_{12,36}=6.09, P<\right.$ 0.0001 ; Fig. $2 \mathrm{~F})$, and injections earned $\left(\mathrm{F}_{9,27}=4.27, P<0.01\right.$; Fig. 2I). Similar to $\Delta^{9}$-THC, rimonabant produced a dosedependent decrease in food pellets earned early in the session, which coincided with a significant increase in the number of $0.003 \mathrm{mg} / \mathrm{kg}$ cocaine injections earned in component 2 .

To further evaluate the effects of CP 55,940 on cocaine choice, the best dose was administered for seven consecutive sessions, immediately before the session. The acute effects of 
A

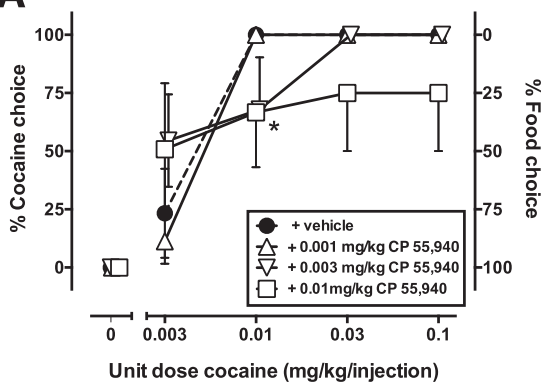

B

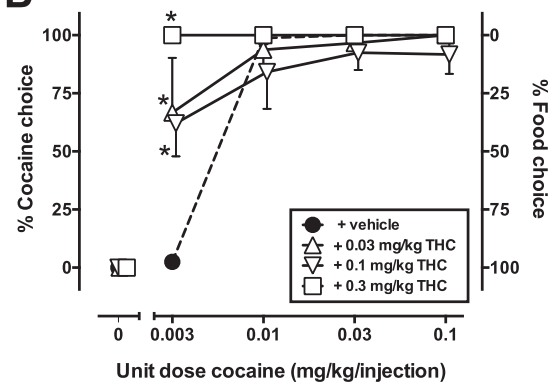

C

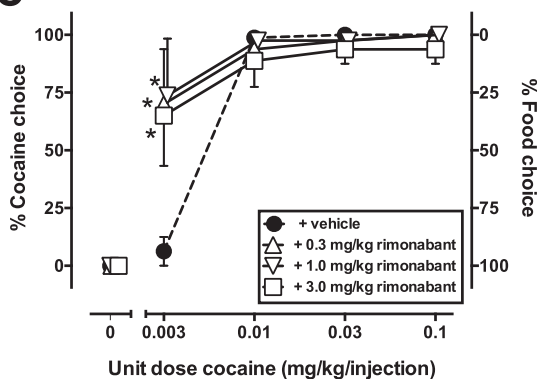

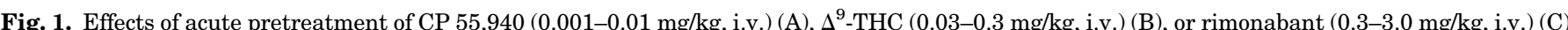

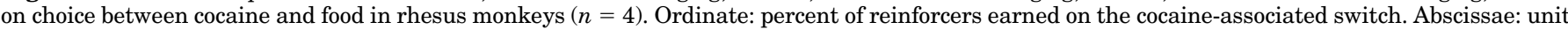

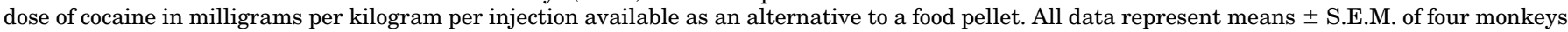

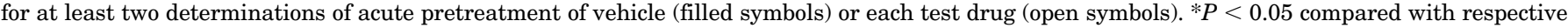
vehicle pretreatment.

the CP 55,940 "best dose" on cocaine choice, determined prior to 7-day treatment (Fig. 3, triangles), showed a downward shift in cocaine choice, which reached significance when $0.01 \mathrm{mg} / \mathrm{kg}$ cocaine was available. Tolerance developed to this effect after 7-day treatment (Fig. 3, squares), resulting in a significant increase in percent cocaine choice when the lowest dose was available $(0.003 \mathrm{mg} / \mathrm{kg}$ cocaine $)$.

\section{Discussion}

Results from this study indicated that cannabinoid modulation of food-cocaine choice differed as a function of the pharmacological efficacy at the cannabinoid receptor. That is, acute pretreatment with a nonselective cannabinoid receptor partial agonist ( $\Delta^{9}$-THC) and inverse agonist/antagonist (rimonabant) were qualitatively similar such that both potentiated the reinforcing effects of cocaine by increasing cocaine choice at low doses. In contrast, acute administration of a nonselective full cannabinoid receptor agonist (CP 55,940) shifted the cocaine choice dose-response curve downward, thereby reducing cocaine choice. Chronic (7-day) treatment with an effective dose of CP 55,940 resulted in tolerance to the CP 55,940-induced decreases in cocaine choice.

The reduction in cocaine choice and reallocation of behavior toward food reinforcement after acute CP 55,940 pretreatment suggests that the relative reinforcing efficacy of cocaine was decreased under the present conditions. It should be noted that these effects also corresponded with an initial decrease in food-maintained responding early in the session and a marginal increase in low-dose $(0.003 \mathrm{mg} / \mathrm{kg})$ cocaine injections; however, this effect did not result in a significant increase in choice of this low cocaine dose. These data suggest that CP 55,940 pretreatment produced initial and transient reinforcement-independent rate-altering effects (e.g., motor impairment) prior to decreasing cocaine choice that may have manifested in an initial increase in cocaine injections as a response to counteract these effects.

One other study has also reported cannabinoid agonistinduced decreases in cocaine self-administration (Fattore et al., 1999). This study showed that acute pretreatment with the synthetic cannabinoid agonist WIN 55,212 dosedependently decreased cocaine self-administration under an FR1 schedule of reinforcement in rats, although only doses on the descending limb of the cocaine dose-response curve were tested. It is possible that these results were due to reinforcement-independent rate-decreasing effects of WIN 55,212 as it was not also tested on responding maintained by a nondrug reinforcer. Therefore, our study extends these findings through the utilization of a concurrent food-cocaine choice procedure to demonstrate that cannabinoid receptor agonist-induced decreases to cocaine self-administration can occur independently of any nonselective rate-decreasing effects of the drug. Other preclinical studies have also shown that the behavioral effects of cocaine were attenuated by pretreatment with full cannabinoid receptor agonists. For instance, WIN 55,212 dose-dependently reduced facilitation of brain stimulation reward in rats as assessed by intracranial self-stimulation (Vlachou et al., 2003) and attenuated cocaineinduced hyperlocomotion in rats (Przegaliński et al., 2005; Vlachou et al., 2008). One possible explanation for cannabinoid agonists to reduce the behavioral effects of cocaine may be associated with CB1 receptor stimulation acting to counteract or attenuate the increased extracellular DA concentrations in the nucleus accumbens produced by cocaine (Centonze et al., 2004). Nevertheless, some studies indicate that cannabinoid receptor antagonists have qualitatively similar effects (i.e., attenuation) on cocaine-induced intracranial selfstimulation (Xi et al., 2008) and hyperlocomotion (Cheer et al., 2007; Corbillé et al., 2007; Gerdeman et al., 2008) as the aforementioned studies with cannabinoid receptor agonists. Thus, it has been proposed that these apparently contradictory findings may indicate an inverted U-shaped curve regarding the effects of $\mathrm{CB} 1$ receptor stimulation on the behavioral effects of cocaine (Olière et al., 2013).

Using models of reinforcing strength (i.e., current choice or $\mathrm{PR}$ schedules of reinforcement), investigators have shown that chronic administration of $d$-amphetamine can produce sustained decreases in cocaine self-administration (e.g., Negus, 2003; Czoty et al., 2010, 2011). As a result, we tested the dose of CP 55,940 that decreased cocaine choice, individually determined for each monkey, for seven consecutive sessions. In contrast to the positive outcomes observed with $d$-amphetamine, we observed tolerance to the decreases in cocaine choice and subsequent increases in choice at the lower doses. The mechanisms for the acute effects of CP 55,940 and the subsequent tolerance to those effects are not clear. There does not appear to be any preclinical studies that examined the effects of CP 55,940 on extracellular DA concentrations. There is relatively weak evidence that acute $\Delta^{9}$-THC, under some conditions, can elevate DA (reviewed by Bloomfield et al. 
A

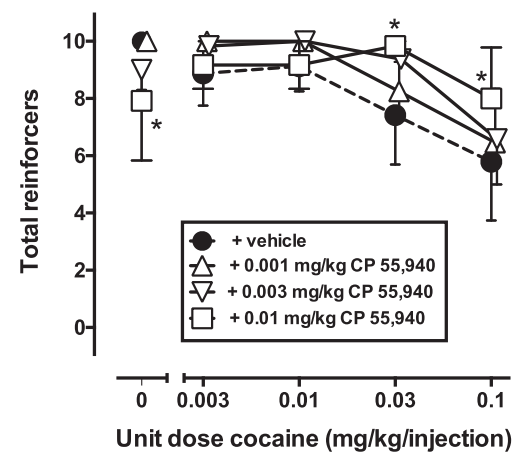

D

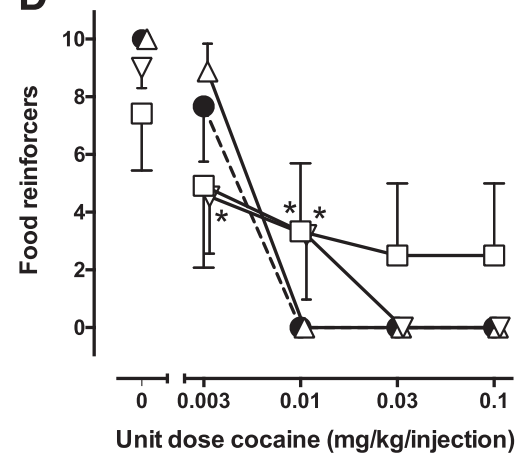

G

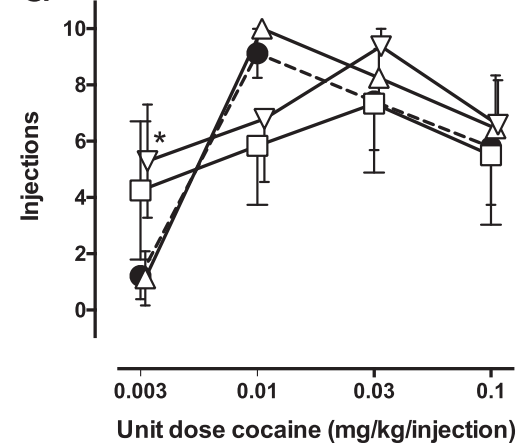

B

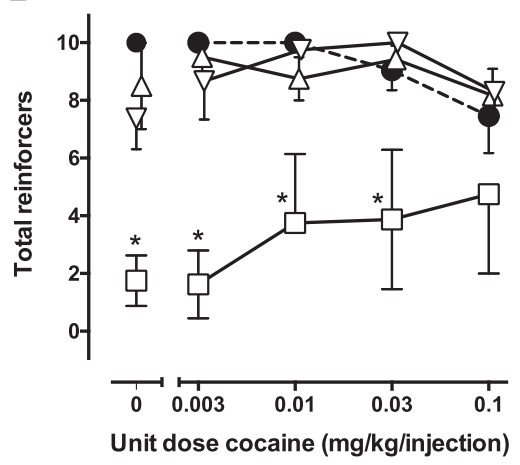

E

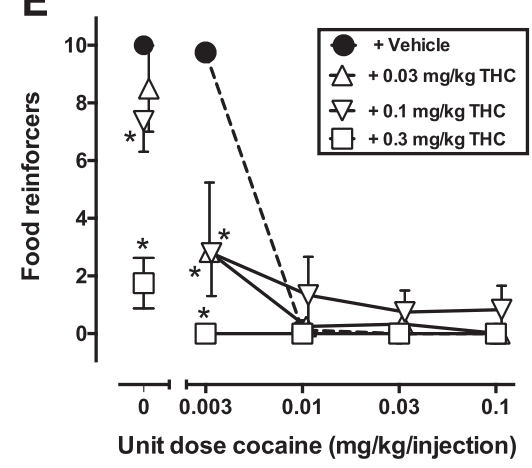

H

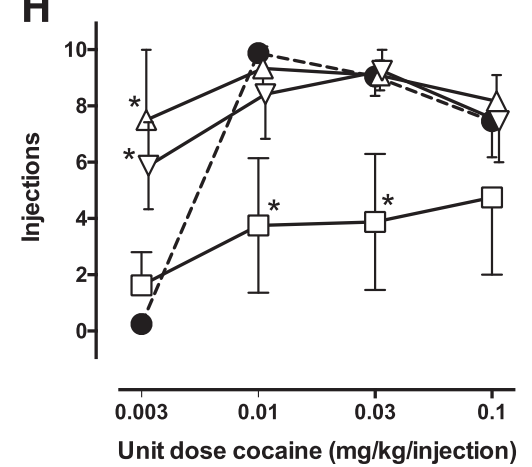

C

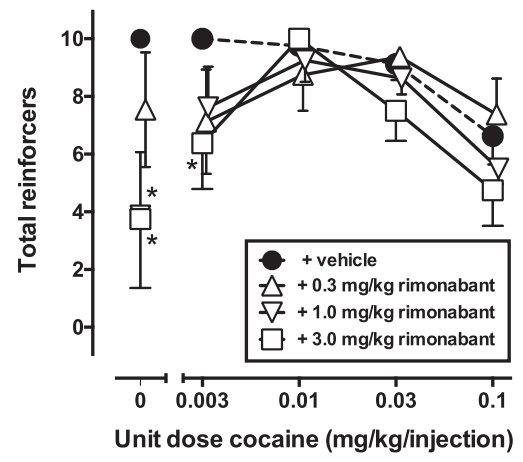

$\mathbf{F}$

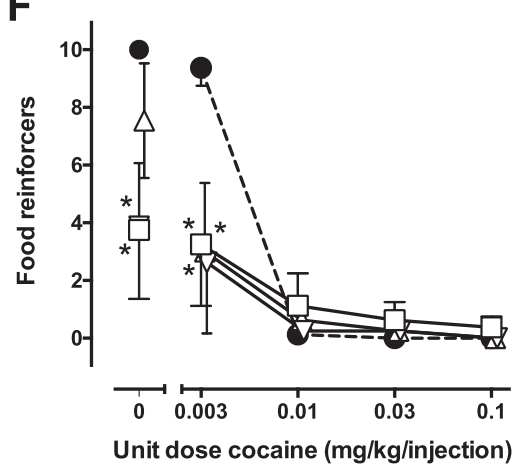

I

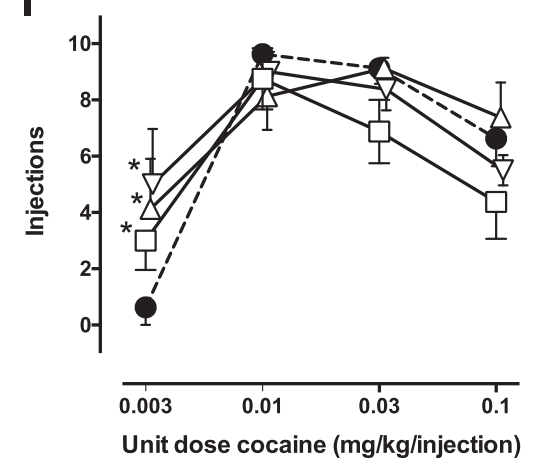

Fig. 2. Effects on total reinforcers earned (A-C), food pellets earned (D-F), or total injections earned (G-I) of acute pretreatment of CP 55,940 (0.001-0.01 mg/kg, i.v.) (A, D, G), $\Delta^{9}$-THC (0.03-0.3 mg/kg, i.v.) (B, E, H), or rimonabant (0.3-3.0 mg/kg, i.v.) (C, F, I). Ordinate: number of respective reinforcer type earned out of a maximum of 10 available per component. Abscissae: unit dose of cocaine in milligrams per kilogram per injection available as an alternative to a food pellet. All data represent means \pm S.E.M. of four monkeys for at least two determinations of acute pretreatment of vehicle (filled symbols) or each test drug (open symbols). ${ }^{*} P<0.05$ compared with respective vehicle pretreatment.

(2016) and Thiruchselvam et al. (2017)), so it is possible that a full agonist like CP 55,940 would produce larger and more robust effects on DA. Whether these effects on DA are diminished with chronic treatment is an important mechanistic question.

Our finding that acute rimonabant increased cocaine choice is in contrast to previous studies that showed rimonabant reduced the reinforcing efficacy of cocaine under a PR schedule in rodents (Soria et al., 2005; Orio et al., 2009). One possible explanation for these discrepant findings may be that cocaine self-administration in the context of a choice paradigm was relatively less confounded by reinforcement-independent ratedecreasing effects of rimonabant. Instead, our findings suggest that increases in self-administration of low doses of cocaine $(0.003 \mathrm{mg} / \mathrm{kg}$ per injection) may have occurred to counteract the rate-decreasing effects of rimonabant early in the session similar to what was observed with CP 55,940. Other factors to be considered for contrasting findings may also include species differences and route of rimonabant administration (intraperitoneal in rodents vs. intravenous in the present study). One possible explanation, which should be tested in future studies, is that the effects of cannabinoid antagonism using rimonabant on cocaine self-administration are influenced by the schedule of reinforcement controlling cocaine self-administration. In particular, measures of reinforcing efficacy of cocaine may be more sensitive to the effects of cannabinoid antagonism, despite qualitative differences between our study using a choice procedure versus prior studies using PR reinforcement schedules, considering many studies using FR schedules of reinforcement show no effect 


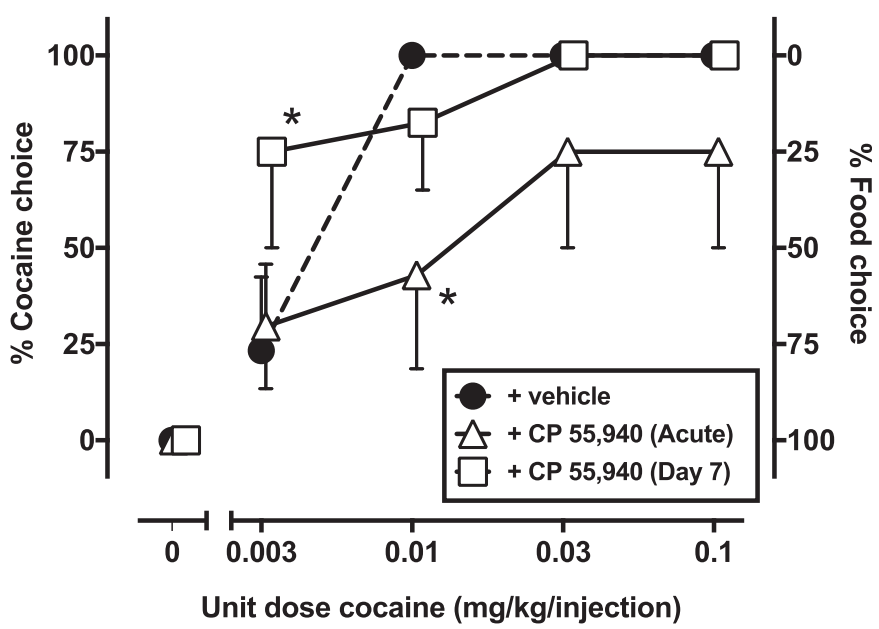

Fig. 3. Effects of acute (open triangles) and day 7 of chronic treatment (open squares) of CP 55,940 on percent cocaine choice. The dose of CP 55,940 was individually determined (see text). All data represent means \pm S.E.M. of four monkeys. Other details are as described in Fig. 1 . $* P<0.05$ compared with respective vehicle pretreatment.

(Tanda et al., 2000; De Vries et al., 2001; Caillé and Parsons, 2006; Filip et al., 2006).

Our finding that acute administration of $\Delta^{9}$-THC increased cocaine choice is consistent with studies in humans examining the acute effects of smoked cannabis prior to cocaine administration. For example, findings from Foltin et al. suggested that smoking marijuana before intravenous cocaine administration (16-32 mg) prolonged subjective effects (i.e., "stimulation," "high") associated with cocaine (Foltin et al., 1993). Another study in humans showed that smoking marijuana 30 minutes prior to intranasal cocaine $(0.9 \mathrm{mg} / \mathrm{kg})$ administration significantly reduced the latency of cocaineinduced effects and increased the duration of cocaine-related euphoric effects (Lukas et al., 1994). Pharmacokinetic factors may have been associated with these findings such that THC-induced vasodilatation led to increased cocaine absorption (Lukas et al., 1994). In contrast, a previous study in rodents showed that $\Delta^{9}$-THC decreased the reinforcing efficacy of cocaine under a PR reinforcement schedule (Panlilio et al., 2007). However, the generalizability of these findings to the present study are limited such that cocaine selfadministration did not occur in the presence of acute $\Delta^{9}$ THC administration but rather after a period of daily $\Delta^{9}$-THC exposure. Furthermore, our study suggests that increased cocaine self-administration may have also occurred to counteract the rate-decreasing effects of high $\Delta^{9}$-THC doses (0.1-0.3 $\mathrm{mg} / \mathrm{kg})$. Nevertheless, pretreatment with the lowest $\Delta^{9}$-THC dose $(0.03 \mathrm{mg} / \mathrm{kg})$ increased cocaine choice without producing significant decreases in food-maintained responding early in the session. These results suggest that the reinforcing efficacy of cocaine was increased independent of a counteracting mechanism associated with "aversive" $\Delta^{9}$ THC effects, at least as it relates to a low THC dose.

In summary, acute administration of a full CBR agonist (CP $55,940)$ decreased cocaine choice, whereas acute administration of a CBR partial agonist $\left(\Delta^{9}\right.$-THC) and antagonist (rimonabant) increased cocaine choice. Tolerance to the effects of CP 55,940 was observed after 7 days of daily treatment. The present study adds to our current understanding of the interaction between cannabinoids and cocaine by demonstrating an additional context (i.e., concurrent food-cocaine choice) for cannabinoid receptor compounds to modulate the reinforcing efficacy of cocaine. Additional studies are warranted to better understand the influence of specific cannabinoid receptor subtypes, considering evidence to suggest that cannabinoid type 1 and 2 receptors may have distinct effects in regulating the abuse-related effects of cocaine (Delis et al., 2017). Future studies employing choice procedures may also consider the use of alternative nondrug reinforcers other than food given the anorectic/orexigenic effects of cannabinoids. Research shows that cannabis is widely used by cocaine users (Jutras-Aswad et al., 2010), and one study showed that over one-fourth of patients with cocaine use disorder had a concurrent cannabis use disorder (John et al., 2018). A study among individuals with cocaine dependence who received treatment in an inpatient program found that cannabis use after discharge from the program was associated with increased relapse to cocaine use (Aharonovich et al., 2005). These negative implications of cannabis use on cocaine treatment outcomes are supported by the present findings indicating a $\Delta^{9}$-THC-induced increase in cocaine choice; however, chronic $\Delta^{9}$-THC studies are clearly necessary.

\section{Acknowledgments}

The authors thank Michael Coller, Jillian Odom, and Susan Nader for assistance with these studies.

\section{Authorship Contributions}

Participated in research design: John, Martin, Nader.

Conducted experiments: John.

Performed data analysis: John.

Wrote or contributed to writing of the manuscript: John, Martin, Nader.

\section{References}

Adamczyk P, Miszkiel J, McCreary AC, Filip M, Papp M, and Przegaliński E (2012) The effects of cannabinoid CB1, CB2 and vanilloid TRPV1 receptor antagonists on cocaine addictive behavior in rats. Brain Res 1444:45-54.

Aharonovich E, Liu X, Samet S, Nunes E, Waxman R, and Hasin D (2005) Postdischarge cannabis use and its relationship to cocaine, alcohol, and heroin use: a prospective study. Am J Psychiatry 162:1507-1514.

Banks ML and Negus SS (2012) Preclinical determinants of drug choice under concurrent schedules of drug self-administration. Adv Pharmacol Sci 2012:281768.

Banks ML and Negus SS (2017) Insights from preclinical choice models on treating drug addiction. Trends Pharmacol Sci 38:181-194.

Bloomfield MA, Ashok AH, Volkow ND, and Howes OD (2016) The effects of $\Delta^{9}$-tetrahydrocannabinol on the dopamine system. Nature 539:369-377.

Caillé S and Parsons LH (2006) Cannabinoid modulation of opiate reinforcement through the ventral striatopallidal pathway. Neuropsychopharmacology 31: 804-813.

Centonze D, Battista N, Rossi S, Mercuri NB, Finazzi-Agrò A, Bernardi G, Calabresi $\mathrm{P}$, and Maccarrone M (2004) A critical interaction between dopamine D2 receptors and endocannabinoids mediates the effects of cocaine on striatal gabaergic Transmission. Neuropsychopharmacology 29:1488-1497.

Cheer JF, Wassum KM, Sombers LA, Heien ML, Ariansen JL, Aragona BJ, Phillips $\mathrm{PE}$, and Wightman RM (2007) Phasic dopamine release evoked by abused substances requires cannabinoid receptor activation. J Neurosci 27:791-795.

Comer SD, Ashworth JB, Foltin RW, Johanson CE, Zacny JP, and Walsh SL (2008) The role of human drug self-administration procedures in the development of medications. Drug Alcohol Depend 96:1-15.

Corbillé AG, Valjent E, Marsicano G, Ledent C, Lutz B, Hervé D, and Girault JA (2007) Role of cannabinoid type 1 receptors in locomotor activity and striatal signaling in response to psychostimulants. $J$ Neurosci 27:6937-6947.

Czoty PW, Gould RW, Martelle JL, and Nader MA (2011) Prolonged attenuation of the reinforcing strength of cocaine by chronic $d$-amphetamine in rhesus monkeys. Neuropsychopharmacology 36:539-547.

Czoty PW, Martelle JL, and Nader MA (2010) Effects of chronic d-amphetamine administration on the reinforcing strength of cocaine in rhesus monkeys. Psychopharmacology (Berl) 209:375-382.

Delis F, Polissidis A, Poulia N, Justinova Z, Nomikos GG, Goldberg SR, and Antoniou $\mathrm{K}$ (2017) Attenuation of cocaine-induced conditioned place preference and motor activity via cannabinoid CB2 receptor agonism and CB1 receptor antagonism in rats. Int $J$ Neuropsychopharmacol 20:269-278. 
De Vries TJ, Shaham Y, Homberg JR, Crombag H, Schuurman K, Dieben J, Vanderschuren LJ, and Schoffelmeer AN (2001) A cannabinoid mechanism in relapse to cocaine seeking. Nat Med 7:1151-1154.

Fattore L, Martellotta MC, Cossu G, Mascia MS, and Fratta W (1999) CB1 cannabinoid receptor agonist WIN 55,212-2 decreases intravenous cocaine selfadministration in rats. Behav Brain Res 104:141-146.

Filip M, Gołda A, Zaniewska M, McCreary AC, Nowak E, Kolasiewicz W, and Przegaliński E (2006) Involvement of cannabinoid CB1 receptors in drug addiction: effects of rimonabant on behavioral responses induced by cocaine. Phar macol Rep 58:806-819.

Foltin RW, Fischman MW, Pippen PA, and Kelly TH (1993) Behavioral effects of cocaine alone and in combination with ethanol or marijuana in humans. Drug Alcohol Depend 32:93-106.

Friedman AL, Meurice C, and Jutkiewicz EM (2019) Effects of adolescent $\Delta 9$ tetrahydrocannabinol exposure on the behavioral effects of cocaine in adult Sprague-Dawley rats. Exp Clin Psychopharmacol 27:326-337.

Gerdeman GL, Schechter JB, and French ED (2008) Context-specific reversal of cocaine sensitization by the CB1 cannabinoid receptor antagonist rimonabant. Neuropsychopharmacology 33:2747-2759.

Gobira PH, Oliveira AC, Gomes JS, da Silveira VT, Asth L, Bastos JR, Batista EM, Issy $\mathrm{AC}$, Okine $\mathrm{BN}$, de Oliveira $\mathrm{AC}$, et al. (2019) Opposing roles of $\mathrm{CB}_{1}$ and $\mathrm{CB}_{2}$ cannabinoid receptors in the stimulant and rewarding effects of cocaine. $\mathrm{Br}$ $J$ Pharmacol 176:1541-1551

Haney M and Spealman R (2008) Controversies in translational research: drug selfadministration. Psychopharmacology (Berl) 199:403-419.

Heyman GM (2009) Addiction: A Disorder of Choice, Harvard University Press, Cambridge, MA.

Higuera-Matas A, Soto-Montenegro ML, del Olmo N, Miguéns M, Torres I, Vaquero JJ, Sánchez J, García-Lecumberri C, Desco M, and Ambrosio E (2008) Augmented acquisition of cocaine self-administration and altered brain glucose metabolism in adult female but not male rats exposed to a cannabinoid agonist during adolescence. Neuropsychopharmacology 33:806-813.

John WS, Newman AH, and Nader MA (2015) Differential effects of the dopamine D3 receptor antagonist PG01037 on cocaine and methamphetamine self-administration in rhesus monkeys. Neuropharmacology 92:34-43.

John WS, Zhu H, Mannelli P, Schwartz RP, Subramaniam GA, and Wu LT (2018) Prevalence, patterns, and correlates of multiple substance use disorders among adult primary care patients. Drug Alcohol Depend 187:79-87.

Justinova Z, Mangieri RA, Bortolato M, Chefer SI, Mukhin AG, Clapper JR, King AR, Redhi GH, Yasar S, Piomelli D, et al. (2008) Fatty acid amide hydrolase inhibition heightens anandamide signaling without producing reinforcing effects in primates Biol Psychiatry 64:930-937.

Jutras-Aswad D, Zang G, and Bruneau J (2010) Cannabis use correlates of syringe sharing among injection drug users. Am J Addict 19:231-237.

Lesscher HM, Hoogveld E, Burbach JP, van Ree JM, and Gerrits MA (2005) Endogenous cannabinoids are not involved in cocaine reinforcement and development of cocaine-induced behavioural sensitization. Eur Neuropsychopharmacol 15: 31-37.

Lukas SE, Sholar M, Kouri E, Fukuzako H, and Mendelson JH (1994) Marihuana smoking increases plasma cocaine levels and subjective reports of euphoria in male volunteers. Pharmacol Biochem Behav 48:715-721.

Negus SS (2003) Rapid assessment of choice between cocaine and food in rhesus monkeys: effects of environmental manipulations and treatment with d-amphetamine and flupenthixol. Neuropsychopharmacology 28:919-931.
Olière S, Joliette-Riopel A, Potvin S, and Jutras-Aswad D (2013) Modulation of the endocannabinoid system: vulnerability factor and new treatment target for stimulant addiction. Front Psychiatry 4:109.

Orio L, Edwards S, George O, Parsons LH, and Koob GF (2009) A role for the endocannabinoid system in the increased motivation for cocaine in extended-access conditions. J Neurosci 29:4846-4857.

Panlilio LV, Solinas M, Matthews SA, and Goldberg SR (2007) Previous exposure to THC alters the reinforcing efficacy and anxiety-related effects of cocaine in rats. Neuropsychopharmacology 32:646-657.

Parsons LH and Hurd YL (2015) Endocannabinoid signalling in reward and addiction. Nat Rev Neurosci 16:579-594.

Przegaliński E, Göthert M, Frankowska M, and Filip M (2005) WIN 55,212-2-induced reduction of cocaine hyperlocomotion: possible inhibition of 5-HT(3) receptor function. Eur $J$ Pharmacol 517:68-73.

Soria G, Mendizábal V, Touriño C, Robledo P, Ledent C, Parmentier M, Maldonado $\mathrm{R}$, and Valverde $\mathrm{O}$ (2005) Lack of CB1 cannabinoid receptor impairs cocaine selfadministration. Neuropsychopharmacology 30:1670-1680.

Tanda G, Munzar P, and Goldberg SR (2000) Self-administration behavior is maintained by the psychoactive ingredient of marijuana in squirrel monkeys. Nat Neurosci 3:1073-1074.

Thiruchselvam T, Malik S, and Le Foll B (2017) A review of positron emission tomography studies exploring the dopaminergic system in substance use with a focus on tobacco as a co-variate. Am J Drug Alcohol Abuse 43:197-214.

Vlachou S, Nomikos GG, and Panagis G (2003) WIN 55,212-2 decreases the reinforcing actions of cocaine through CB1 cannabinoid receptor stimulation. Behav Brain Res 141:215-222.

Vlachou S and Panagis G (2014) Regulation of brain reward by the endocannabinoid system: a critical review of behavioral studies in animals. Curr Pharm Des 20:2072-2088.

Vlachou S, Stamatopoulou F, Nomikos GG, and Panagis G (2008) Enhancement of endocannabinoid neurotransmission through CB1 cannabinoid receptors counteracts the reinforcing and psychostimulant effects of cocaine. Int $J$ Neuropsychopharmacol 11:905-923.

Wang H, Treadway T, Covey DP, Cheer JF, and Lupica CR (2015) Cocaine-induced endocannabinoid mobilization in the ventral teomental area Cell Rep 12:1997-2008.

Ward SJ, Rosenberg M, Dykstra LA, and Walker EA (2009) The CB1 antagonist rimonabant (SR141716) blocks cue-induced reinstatement of cocaine seeking and other context and extinction phenomena predictive of relapse. Drug Alcohol Depend 105:248-255.

Wiskerke J, Pattij T, Schoffelmeer AN, and De Vries TJ (2008) The role of CB1 receptors in psychostimulant addiction. Addict Biol 13:225-238.

Xi ZX, Gilbert JG, Peng XQ, Pak AC, Li X, and Gardner EL (2006) Cannabinoid CB1 receptor antagonist AM251 inhibits cocaine-primed relapse in rats: role of glutamate in the nucleus accumbens. $J$ Neurosci 26:8531-8536.

Xi ZX, Spiller K, Pak AC, Gilbert J, Dillon C, Li X, Peng XQ, and Gardner EL (2008) Cannabinoid CB1 receptor antagonists attenuate cocaine's rewarding effects: experiments with self-administration and brain-stimulation reward in rats. $\mathrm{Neu}$ ropsychopharmacology 33:1735-1745.

Address correspondence to: Dr. Michael A. Nader, Department of Physiology and Pharmacology, Wake Forest School of Medicine, 546 NRC, Medical Center Boulevard, Winston-Salem, NC 27157-1083. E-mail: mnader@ wakehealth.edu 